\title{
Natural experiments in rock mechanics using high precision monitoring of chalk sea cliffs
}

\author{
J. Barlow*1, R. Moore ${ }^{1}$, J. Gilham ${ }^{1}$ \\ ${ }^{1}$ University of Sussex, Brighton, United Kingdom \\ ${ }^{*}$ Corresponding Author
}

\begin{abstract}
Prediction of rock slide events remains a difficult task for geoscientists. Kinematic analysis provides an indication of possible modes of failure at a site. However, the highly variable nature of chalk compressive strength due to variations in water content and salt weathering is such that parameterizing models of slope stability can result in large variations in the resultant factor of safety. In this work, we use high-precision monitoring data of an eroding coastal cliff to characterize the geometry a large wedge failure in chalk. We use these data in conjunction with published material properties to model the joint compressive strength of the chalk at the time of failure through back analysis. Results indicate a strength of $7.19 \mathrm{KPa}$ for the chalk suggesting that the joint surface was close to saturation at the time of failure.
\end{abstract}

\section{INTRODUCTION}

The structural geology of cliffs provides primary control over the type of slope failure that may occur. This is because the uniaxial compressive and shear strength of penetrative discontinuities are generally lower than those of the intact rock (Terzaghi, 1962). Slope stability modelling of brittle rock is typically undertaken using a limit equilibrium approach whereby stability is a function of body forces and the shear strength of discontinuities (joints) that bound the potential failure mass (Wyllie \& Mah, 2004). Several models have been proposed to quantify the shear strength of joints, the most commonly used being the Mohr-Coulomb and Barton-Bandis models (Hencher \& Richards, 2015). Research into the strength properties of medium-hard chalk indicate compressive strength can vary from 5 to $15 \mathrm{MPa}$ based on the water content of the sample (Mortimore et al. 2004a), with a further reduction of up to $54.1 \%$ due to sea salt saturation and the growth of salt crystals (Lawrence et al.,
2013). Operationally, it is difficult to apply these relationships as sampling changing water content and salt concentrations across joint surfaces prior to failure is cost prohibitive. Consequentially, the ability to mitigate against potential slope failures is often based on incomplete information.

Tucker (2009) defines a natural experiment in landform development as a case study in which the initial/boundary conditions are well constrained and only one parameter varies significantly within the system. A common approach to this within landslide research is back analysis, in which the ratio of driving and resisting forces is assumed to be 1 at the point of failure (Wyllie \& Mah, 2004). We apply this concept to eroding sea cliffs in order to examine the strength of chalk at a scale that cannot be replicated through laboratory testing. The Barton-Bandis model of shear failure calculates the shear strength of joints $(\tau)$ based on the residual friction angle $\left(\varphi_{r}\right)$, the joint-wall compressive strength $(J C S)$, the joint roughness coefficient $(J R C)$, and the normal force $\left(\sigma_{n}\right)$ such that (Barton 2013): 


$$
\tau=\sigma_{n} \tan \left[J R C \log _{10}\left(\frac{J C S}{\sigma_{n}}\right)+\varphi_{r}\right]
$$

Equation 1 assumes a planar shear surface with second-order asperities based on JRC. However, many joint surfaces exhibit first-order asperities or waviness. This waviness is defined as the maximum difference between the slope of asperities and the mean slope. These act to increase $\tau$ in equation 1 according to (Miller, 1988):

$$
\tau=[1]+\sigma_{n} \tan [\text { waviness }]
$$

In this research, we use well-established material properties for chalk in conjunction with failure geometry data derived from high-precision monitoring to establish the JCS of Newhaven Chalk through back analysis.

\section{STUDY AREA}

Telscombe Cliffs are one of the few remaining undefended sections of coastline between Brighton and Newhaven in East Sussex, UK (Figure 1). Rising to a maximum elevation of $49 \mathrm{~m}$, the cliffs are $750 \mathrm{~m}$



Figure 1: Telscombe study area with cross sectional profile of the cliffs provided below. Red area indicates the location of the wedge failure used in this study.

long and are formed from Cretaceous Chalk of the Newhaven and Culver Formations (Mortimore, 1997). The cliffs are orientated to the south-west facing the dominant wave direction. To the east, the site is bounded by the sewage outfall pipe, which is protected by a concrete groyne and provides an artificial barrier to the movement of beach sediments. As a consequence of this, the eastern portion of the cliff line is protected at the toe by a substantial pebble beach which tapers over approximately $300 \mathrm{~m}$ to the west (Figure 1). At both ends of the site, the cliffs have been artificially regraded and disconnected from marine interaction through the construction of a sea wall and promenade. The site is macro tidal with an average spring tidal range of $6.1 \mathrm{~m}$ (CCO, 2017), submerging the shore platform and allowing wave interaction with the base of the cliff. Significant wave heights $\left(\mathrm{H}_{\mathrm{s}}\right)$ measured from the wave buoy at Seaford, show an average of $0.64 \mathrm{~m}$ in summer and $1.04 \mathrm{~m}$ in winter $(\mathrm{CCO}$, 2017). Average annual precipitation is $720 \mathrm{~mm}$ with the majority falling in the winter months. The combination of winter storm waves and wet weather weaken the chalk such that rockfalls are most common in winter months (Mortimer et al., 2004a; Brossard and Duperret, 2004).

Newhaven Chalk is characterized by steeply inclined conjugate joint sets (Mortimore et al., 2004b). These, in conjunction with various bedding planes provide discernible controls on the type and magnitude of failures along this stretch of coastline (Mortimore et al., 2004b). Barlow et al. (2017) undertook kinematic analysis of these cliffs. Results indicate two major joint sets, joint set 1 (JS1) and joint set 2 (JS2) with mean dip/dip direction of $75^{\circ} / 169^{\circ}$ and $78^{\circ} / 233^{\circ}$ respectively. The mean dip/dip direction of the cliff face is $76^{\circ} / 204^{\circ}$ such that wedge failure is indicated (Barlow et al. 2017). Indeed, a large wedge failure involving sliding across both joint sets occurred at Telscombe on March $1^{\text {st }} 2017$ (Figure 1) and forms the basis for our analysis. Antecedent rainfall for the two days leading up to failure was $17.9 \mathrm{~mm}$ and mean $\mathrm{H}_{\mathrm{s}}$ for the same period was $2.75 \mathrm{~m}$ during periods of high tide (CCO, 2017).

\section{METHODS}

This research forms part of an on-going monitoring project into coastal erosion along Telscombe Cliffs using UAV photogrammetry. Monthly surveys have been undertaken from July 2016 to present. Our methods involve the use of dense point clouds derived from the UAV photogrammetry data to constrain the geometry of the wedge failure. This section is subdivided 
based on the relevant stages of the workflow, these were: installation of ground control, UAV survey, photogrammetric processing, change detection, extraction of joint properties, and back analysis.

\subsection{Ground Control}

Georeferencing of our models involved 23 ground control points (GCPs), 5 at the cliff top and 18 at the cliff toe (Figure 1). Differential global positioning system (dGPS) was used to locate cliff top GCPs at 5 locations and to set up total station survey markers on the shore platform. Ground control at the cliff toe required the use of a total station in order to overcome the reduction in dGPS accuracy due to the 'shadowing' effect of the cliff, a common issue seen in complex terrain morphologies (Young, 2012). After processing (Awange \& Kiema, 2013) the dGPS points were accurate to $0.02 \mathrm{~m}$ in the $x, y$ and $z$ planes with PDOPs varying between 1.2 and 1.5. Total station surveying was used to obtain the cliff toe positions at equidistant locations along the base of the cliff, back sight locations were dual measured pre and post survey to attain an uncertainty value. The maximum deviation from the known dGPS back sight coordinates was $0.006 \mathrm{~m}$ such that the maximum error of our GCPs was within about $0.03 \mathrm{~m}$.

\subsection{UAV survey}

The characterization of sub-vertical slopes using digital photogrammetry is typically successful if a fine $(\mathrm{cm})$ to very fine $(\mathrm{mm})$ resolution is obtained (Sturzenegger and Stead, 2009b). Birch (2006) noted that a ground pixel size of $0.01 \mathrm{~m}$, together with an expected image accuracy of 0.5 pixels is a good conservative value for engineering photogrammetric planning. Mapping at this resolution makes it possible to detect and measure low to extremely high persistence discontinuities (Sturzenegger and Stead, 2009a,b).

Total flight time for each survey was 8 minutes. A full frame Nikon D810 36 mega-pixel camera was used for the surveys with a Nikkor $24 \mathrm{~mm} \mathrm{f} / 2.8 \mathrm{D}$ prime lens. Image capture was achieved at a shutter speed at $1 / 5000 \mathrm{~s}$ in order to minimize distortion associated with camera motion. The aircraft used was a DJI S1000 octocopter flying an automated path that maintained a distance of about $50 \mathrm{~m}$ between the camera and the cliff face at a flying height of $21 \mathrm{~m}$. During flight, live streaming video was used to orient the camera orthogonal to cliff face. The UAV was set to fly at a constant speed of $3 \mathrm{~m} \mathrm{~s}^{-1}$ while image capture was set to a time interval of five seconds resulting in a photobase of $15 \mathrm{~m}$ following a strip plan. This technique is an efficient means for mapping a long stretch of cliff line from a relatively close distance with a short focal length (Birch, 2006). Ground control survey markers were installed on the GCPs in order to georeference the models and test model accuracy.

\subsection{Photogrammetric processing}

Photogrammetric modelling was undertaken using ADAM 3DM Mine Mapping Suite (Adam Technology, 2010). The interior orientation is based on camera calibration prepared prior to survey. An exterior orientation was undertaken by digitizing the location of the 23 GCPs to an image accuracy of 0.1 pixels based on the center of the survey control markers. Relative Only (RO) points were automatically generated and a bundle adjustment was run based on these points. Resulting exterior orientations had standard errors ranging from $0.03 \mathrm{~m}$ to $0.06 \mathrm{~m}$. The models had a point density of $\sim 351$ points $/ \mathrm{m}^{2}$.

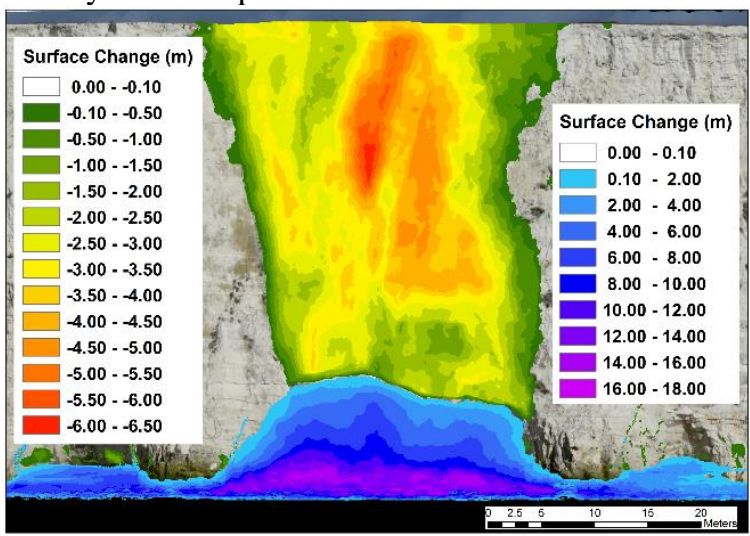

Figure 3: Volumetric analysis of the wedge failure. Negative values indicate erosion.

Erosion along the cliff face was mapped using 2.5 D change detection between sequential surveys (e.g. Rosser et al. 2005). Point cloud data were rasterized to a resolution of $0.1 \mathrm{~m}$ such that each grid cell is based on $\sim 3.5$ points. A subtraction between sequential raster layers was then undertaken as illustrated in Figure 3. A $10 \mathrm{~cm}$ difference threshold was used in order to eliminate false positives. 


\subsection{Extraction of wedge geometry}

The use of dense point clouds derived from closerange digital photogrammetry and terrestrial laser scanning in the characterization of rock slope morphology is well established within the research literature. These methods have the advantage of allowing measurements to be taken from the entire rock surface rather than only those sections accessible to manual measurement (e.g. Sturzenegger \& Stead, 2009a; Salvini et al. 2013). The geometry of shear surfaces was extracted directly from the point cloud data by best fitting a plain to the surface points using least squares regression as shown in Figure 4. The same approach was used to extract a generalized geometry for the tension crack at the rear of the failure and the pre-failure cliff face.

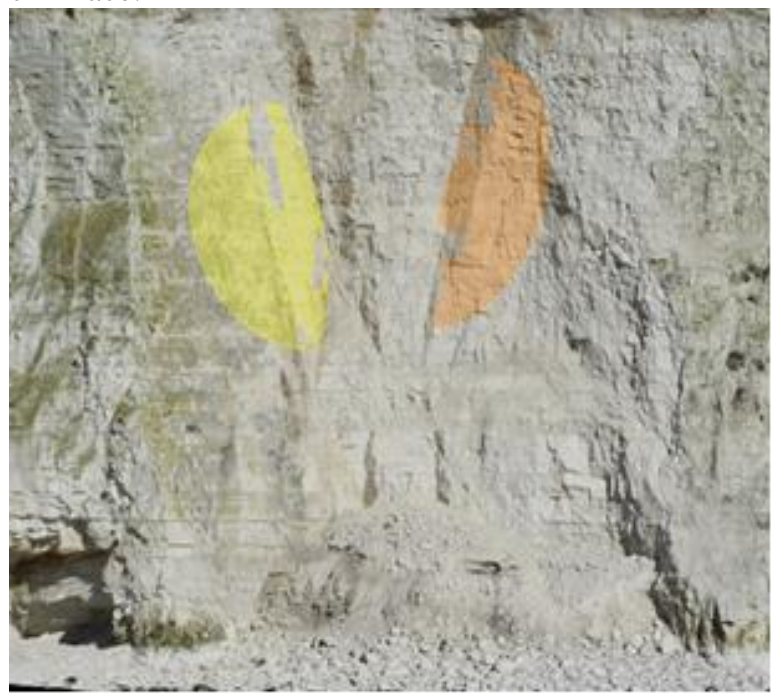

Figure 4: Mapping of the principle shear surfaces involved in the wedge failure. JS1 indicated in yellow and JS2 in orange.

\subsection{Back analysis}

Back analysis was undertaken using a limit equilibrium approach within the Swedge software environment. A detailed description of the numerical formulation is provided in Wyllie \& Mah (2004). The failure mass was generalized based on the two principle shear surfaces bounded by the tension crack at the rear and the cliff face at the front as discussed above. However, the density of the point cloud was insufficient to assess
$J C R$ such that this was done manually in the field using a set of reference profiles (Barton, 2013). Joint waviness was extracted by rasterizing joint surfaces to a resolution of $10 \mathrm{~cm}$ and taking cross sections parallel to the direction of sliding. Three cross sections were taken from each joint surface and the maximum divergence from mean joint slope was extracted as illustrated in Figure 5 and used in the back analysis.

JS1 JS2

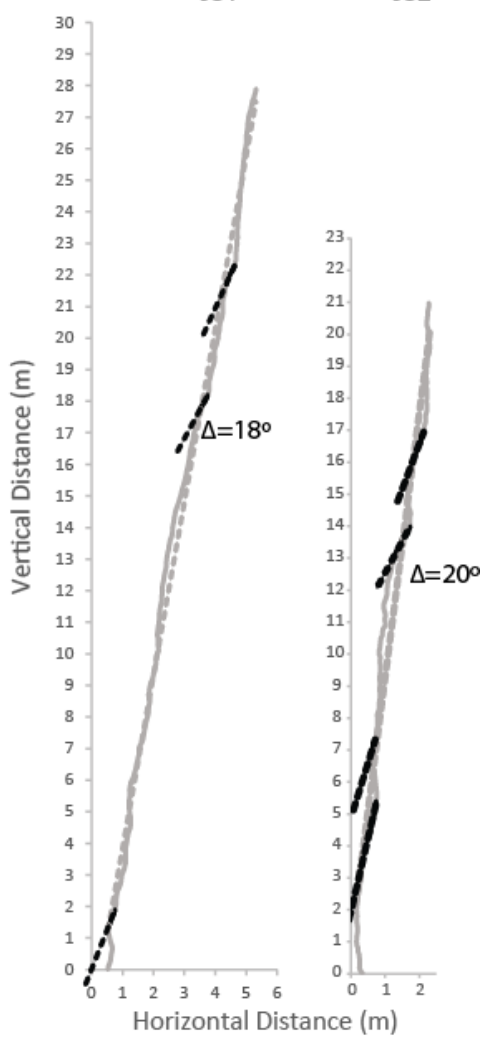

Figure 5: Cross sectional profiles of joint surfaces used to evaluate joint waviness with maximum divergence from mean slope indicated.

\section{RESULTS AND DISCUSSION}

Based on the change detection, the total failure volume was estimated at $2547 \mathrm{~m}^{3}$. However, the lower part of the failure scar was obscured by debris (Figure 
3) such that this is an underestimate. This volume includes a large section on the eastern side of the wedge. A fractographic examination of river lines evident in the chalk at the top of this section indicates failure radiated outwards horizontally from JS2 (Figure 4) suggesting that the failure of this mass was triggered by the initiation of motion in the wedge. Based on the geometries extracted from the point cloud data, the wedge volume is estimated at $669 \mathrm{~m}^{3}$ or $26 \%$ of the total volume.

Profiles extracted from the surfaces of joint sets 1 and 2 are shown in figure 5 . The grey dashed lines indicate the mean slope face across the raster with the black dashed lines showing the slope of large scale undulations on the surface. For the JS1 and JS2, the maximum difference measured was $18^{\circ}$ and $20^{\circ}$ respectively. Joint waviness increases $\tau$ in equation 1 by an amount equal to $\sigma_{n} \tan$ (waviness)

The parameters used in Swedge and their assigned values are listed in table 1 . As indicated, most of these were extracted from the point cloud data. However, residual friction angle and the specific weight were derived from measurements reported in the literature.

Table 1: Parameters used in back analysis

\begin{tabular}{lll}
\hline Parameter & Value & Source \\
\hline JS1 (dip/dip dir) & $74^{\circ} / 165^{\circ}$ & point cloud \\
JS2 (dip/dip dir) & $75^{\circ} / 253^{\circ}$ & point cloud \\
Cliff (dip/dip dir) & $79^{\circ} / 200^{\circ}$ & point cloud \\
Tension Crack & & \\
(dip/dip dir) & $82^{\circ} / 202^{\circ}$ & point cloud \\
JS1 waviness & $18^{\circ}$ & point cloud \\
JS2 waviness & $20^{\circ}$ & point cloud \\
JRC (JS1 \& JS2) & 11 & field \\
JCS (JS1 \& JS2) & $7.19 \mathrm{MPa}$ & back analysis \\
Residual friction & $30^{\circ}$ & Lord et al. 2002 \\
Specific Weight & $0.02 \mathrm{MN} / \mathrm{m}^{3}$ & Mortimore et al 2004a \\
\hline
\end{tabular}

The back analysis indicates sliding across both JS1 and JS1 with the failure mass moving outwards along azimuth $207^{\circ}$ along the line of intersection between the two joints at an angle of $69^{\circ}$. Back analysis indicates a $J C S$ of $7.19 \mathrm{MPa}$ at the time of failure. This is at the lower end of the range of values reported by Mortimore et al., 2004a which suggests that the chalk surrounding the joint surface was near saturation at the time of failure. Antecedent precipitation in the preceding two days measured $17.8 \mathrm{~mm}$. Infiltration of this water along joint surfaces may explain this low JCS value.

\section{CONCLUSIONS}

The large range in chalk strength caused by variations in water content and salt weathering are such that it is difficult to transfer laboratory results into models of slope stability. Back analysis of rock slides in chalk is one means of assessing strength at the time of failure. High precision monitoring data derived from UAV photogrammetry can be a useful tool in back analysis as the failure geometry and joint waviness can be extracted from the point cloud data. The rapid rate of data collection is such that large sections of cliff can be monitored (Barlow et al. 2017). For actively eroding sea cliffs, this suggests that many failures can be sampled over a monitoring period of just a few years.

Our results indicate a JCS of $7.19 \mathrm{MPa}$ for the wedge failure. This value is close to the lower end of the range reported by Mortimore et al (2004) suggesting that the chalk along the shear surfaces was close to saturation prior to failure. Although only a single failure is discussed here, with continued monitoring it will be feasible to build up a database of multiple examples in order to better understand the variability of JCS, $J R C$, and joint waviness. These data can then inform statistical models for each parameter to facilitate better estimates for predicting a factor of safety for potential wedge failures identified in the survey data.

\section{ACKNOWLEDGEMENT}

This research was supported by the Engineering and Physical Sciences Research Council and the University of Sussex Research Development Fund.

\section{REFERENCES}

Awange, J. \& Kiema, J. B. K. 2013. Environmental geoinformatics: monitoring and management. Springer, Berlin.

Barlow, J. Gilham, J. \& Ibarra Cofrã, I. 2017. Kinematic analysis of sea cliff stability using UAV photogrammetry, Int. Journal of Remote Sensing 38 (8-10), 2464-2479.

Barton, N. 2013. Shear strength criteria for rock, rock joints, rockfill and rock masses: Problems and some solutions. Journal of Rock Mech. and Geotechnical Eng. 5, 249-261.

Birch, J.S. 2006. Using 3DM Analyst mine mapping suite for rock face characterization. In: Tonon, F. \& Kottenstette, J. (Eds.), Laser and Photogrammetric Methods for Rock Face Characterization, ARMA. 
Brossard, J. \& Duperret., A. 2004. Coastal Chalk cliff erosion: experimental investigation on the role of marine factors. In: Mortimore, R. \& Duperret, A. (Eds.). Coastal Chalk Cliff Instability. Geological Society, London, Engineering Geology Special Publications 20, 109-120.

CCO (Channel Coastal Observatory). 2017. Regional Coastal Monitoring Programmes Seaford Wave Buoy. Retrieved from: http://www.channelcoast.org.

Hencher, S.R. \& Richards, L.R. 2015. Assessing the shear strength of rock discontinuities at laboratory and field scales. Rock Mech. Rock Eng., 48, 883-905.

Lawrence J.A., Mortimore, R.N., Stone, K. \& Busby J. 2013. Sea salt water weakening of chalk and the impact on cliff instability. Geomorphology, 191, 14-22.

Lord, J.A., Clayton, C.R.I. \& Mortimore, R.N. 2002. Engineering in chalk. Construction Industry Research and Information Association Report, C574.

Miller, S.M. 1988. Modeling Shear Strength at Low Normal Stresses for Enhanced Rock Slope Engineering, Proc. Of 39th Highway Geology Symp., 346-356.

Mortimore, R.N. 1997. The Chalk of Sussex and Kent. The Geologists Association. London.

Mortimore, R.N. Stone, K.J. Lawrence, J. \& Duperret A. 2004a. Chalk physical properties and cliff instability. In: Mortimore, R., \& Duperret, A. (eds.). Coastal Chalk Cliff Instability. Geol. Soc., London: Engineering Geology Special Publications, 20.

Mortimore, R. Lawrence, J. Pope, D. Duperret, A. \& Genter, A. 2004b. Coastal cliff geohazards in weak rock: the UK Chalk cliffs of Sussex. In: Mortimore, R., and Duperret, A. (Eds.). Coastal Chalk Cliff lnstability. Geological Society, London: Engineering Geology Special Publications, 20.

Mortimore R.N. 2012. Making sense of Chalk: a total-rock approach to its Engineering Geology. Quart. Journal of Eng. Geol. and Hydrogeol. 45, 252-334.

Rosser, N.J. Petley, D.N. Lim, M. Sunning, S.A. \& Allison R.J. 2005. Terrestrial laser scanning for monitoring the process of hard rock coastal cliff erosion. Quarterly Journal of Engineering Geology and Hydrogeology 38, 363-375.

Salvini, R. Francioni, M. Riccucci, S. Vonciani, F. \& Callegari, I. 2013. Photogrammetry and laser scanning for analyzing slope stability and rock fall runout along the Domodossola-Iselle railway, the Italian Alps. Geomorphology 185, 110-122.

Stead, D. \& Coggan, J. 2012. Numerical modeling of rock slope instability. In: Clague J.J. \& Stead D. (eds) Landslides Types, Mechanisms and Modeling, 144-158.

Sturzenegger, M. \& Stead, D. 2009a. Close-range terrestrial digital photogrammetry and terrestrial laser scanning for discontinuity characterization on rock cuts. Engineering Geology 106 (3), 163182.

Sturzenegger, M. \& Stead, D. 2009b. Quantifying discontinuity orientation and persistence on high mountain rock slopes and large landslides using terrestrial remote sensing techniques. Natural Hazards and Earth System Sciences 9(2), 267-287.

Terzaghi, K. 1962. Stability of steep slopes on hard unweathered rock. Géotechnique 12 (4), 251-270.

Tucker, G.E. 2009. Natural experiments in landscape evolution. Earth Surface Processes and Landforms 34 (10), 1450-1460.

Wyllie, D.C. \& Mah, C. 2004. Rock slope engineering. CRC Press, London \& New York.
Young, E. 2012. dGPS. In: Cook, S.J. Clarke, L.E. \& Nield, J.M. (Eds.) Geomorphological Techniques (Online Edition). British Society for Geomorphology, London. ISSN: 2047-0371. 